\title{
Controlar ou avaliar o trabalho docente? Estratégias dos diretores numa organização escolar híbrida
}

\author{
ANNE BARRÈRE \\ Universidade de Paris 3 \\ Universidade de Paris 5 \\ Tradução de Michel Guy Abes \\ Revisão técnica de Vanda Mendes \\ Ribeiro e Fernando Scheibe
}

No dia 15 de dezembro de 2011, enquanto este artigo estava sendo redigido, os sindicatos de professores franceses votavam um indicativo de greve contra um projeto de reforma da avaliação do seu desempenho. Esse projeto atribuía exclusivamente aos diretores a competência de avaliar os professores, o que interfere na sua progressão na carreira. Tal episódio atesta que há tensões e questões que se colocam hoje devido à introdução de novos meios de avaliação no sistema educativo francês e corrobora o propósito deste artigo, pois a finalidade da avaliação está intrinsecamente ligada às transformações de uma profissão. No caso, a dos diretores de ensino, particularmente no ensino secundário, ${ }^{1}$ cujo universo profissional está em constante evolução.

A ideia de uma nova forma de realizar a gestão pública, conciliando reforma organizacional e continuidade da instituição, em torno dos valores de igualdade de

1 No ensino primário, a maioria dos diretores de escola franceses continua a ensinar uma parte de seu tempo e, se existem evoluções paralelas, elas são, apesar de tudo, menos marcadas e alternadas com evoluções propriamente estatutárias. $\mathrm{O}$ diretor de escola continua sendo mais um "par". 
oportunidades e de integração das diferenças sociais, molda, desde os anos de 1980, as políticas escolares no âmbito de uma descentralização moderada. Vale lembrar que, na França, os diretores dos estabelecimentos do ensino secundário, chamados principaux, nos colégios que acolhem alunos de 11 a 14 anos, e proviseurs, nos liceus, que acolhem alunos de 15 a 17 anos, não contratam os professores - nomeados após um concurso regido por uma legislação nacional - nem são responsáveis por sua remuneração. Em contrapartida, eles os avaliam em um relatório administrativo, que equivale a $40 \%$ de uma nota global que decide sua progressão na carreira. ${ }^{2}$ Os $60 \%$ restantes advêm de uma avaliação feita em média a cada sete anos por uma inspeção pedagógica especializada na disciplina pela qual o professor é responsável. É preciso lembrar, igualmente, que essa nova organização foi implantada em meio a um processo de descentralização no âmbito do qual os estabelecimentos passaram a definir seus projetos considerando as necessidades locais, ainda que o recrutamento e os programas tenham permanecido nacionais.

Mas, desde os anos 2000, assistimos a duas novas inflexões. Por um lado, as funções dos diretores do ensino secundário passam a ser definidas como sendo explicitamente pedagógicas. $\mathrm{O}$ estabelecimento escolar aparece como uma nova escala de regulação pertinente, intermediária entre o nacional e o local, e dotada de margens de manobra estratégicas. Por outro lado, essas margens de manobra devem, cada vez mais, ser definidas no âmbito de uma problemática onipresente no sistema escolar de hoje: a avaliação. Desde o movimento de modernização do setor público dos anos de 1980, a avaliação é um ponto de conjunção das políticas educativas, por meio de instrumentos de pesquisa em massa encarregados de realizar diagnósticos sobre o sistema escolar de modo a contribuir com o seu monitoramento (Dutercq, 2000; Forestier et al., 2007).

Por meio de testes padronizados de avaliação do desempenho dos alunos, indicadores de avaliação da gestão e listas classificatórias de estabelecimentos escolares publicadas nos jornais, a avaliação se caracteriza pela disponibilização, aos atores envolvidos com a educação escolar, de informações de diferentes naturezas, muitas vezes, sob a forma de indicadores quantitativos, com o objetivo de tornar a ação educativa transparente e mais eficiente. As pesquisas mostram que, na prática, esses indicadores são pouco e mal empregados, até no nível macropolítico (Crahay; Mons, 2011). Mas sua existência contribui para modificar a percepção que os diretores do ensino secundário têm de sua própria profissão, uma parte de seu trabalho consistindo, doravante, em dar verdadeiros pareceres de peritos, a partir dos números sobre a situação de seu estabelecimento.

As relações entre os diretores do ensino secundário e os professores carregam, evidentemente, a marca dessas evoluções. O controle da atividade de ensino se transforma, integrando o nível do estabelecimento, mas também novas preocupações avaliativas que trazem a ideia de desempenho e de eficiência. No entanto,

2 Esta nota é atribuída julgando as competências de ensino em três áreas: assiduidade e pontualidade, autoridade e capacidade de transmissão, eficiência pedagógica. 
essas transformações estão longe de ocorrer de forma unilateral e homogênea. Para mostrar sua complexidade, faremos uso de uma pesquisa qualitativa feita em 40 estabelecimentos de ensino do norte da França, cruzando longas entrevistas semidirecionadas e observações in loco realizadas durante um ano letivo num colégio localizado numa zona educativa prioritária ${ }^{3}$ (Barrère, 2006).

\section{OS DIRETORES DE ESTABELECIMENTOS DE ENSINO SECUNDÁRIO E O ENQUADRAMENTO DO TRABALHO DOCENTE: A EXTENSÃO DO DOMÍNIO DE CONTROLE}

$\mathrm{Na}$ França, aproximadamente três quartos dos diretores de estabelecimentos de ensino secundário são antigos professores deste mesmo nível de ensino. Uma pequena minoria advém do ensino primário ou de outras funções, tais como a de orientador educacional ou documentalista. No sistema, do mesmo modo como funcionava antes da descentralização, o controle do trabalho docente era confundido com o do bom funcionamento da escola. Tratava-se de zelar, no início do processo, para que, numa organização qualificada como sendo parte de um todo, cada professor estivesse na hora certa, na sala certa, durante o tempo desejado. Nessa perspectiva, a sala de aula é uma caixa-preta teórica cujo funcionamento conhece-se informalmente, mas cujo controle é delegado de facto ao inspetor pedagógico, forma que costuma ser chamada de "gestão compartilhada". No decorrer das inspeções, os diretores podem eventualmente assistir às aulas, o que não é o caso mais frequente e pode até ser considerado algo delicado. $O$ controle dos professores pelos diretores incide, então, apenas sobre pequenas falhas, como atrasos, ou sobre problemas profissionais extremos, como quando os professores colocam em perigo a segurança dos alunos.

No entanto, a mudança das funções dos diretores transformou esse conjunto de tarefas, como o mostra bem a evolução da formação profissional, realizada atualmente em parte pelos pares, e em parte pela Escola Superior da Educação Nacional (ESEN), onde atuam inspetores gerais e membros das altas funções públicas. Com efeito, ela se redefiniu em torno de competências de enquadramento precisamente definidas em relação com a nova forma de efetivar a gestão pública. Exercendo sua função no ensino secundário em tempo integral - ao contrário do ensino primário, no qual os diretores de escolas continuam encarregados de uma sala de aula-, os diretores teriam a oportunidade de aprender uma nova profissão de "chefia", em que as competências de animação e de direção de equipes são centrais, assim como aquelas que dizem respeito à avaliação. Tratar-se-ia também de assumir uma postura de poder e de responsabilidade, mesmo se a ausência de

3 Desde os anos de 1980, as políticas de educação prioritária francesas atribuem mais recursos financeiros e humanos aos estabelecimentos cujo meio social é considerado menos favorecido. 
recrutamento e a forma tradicional da avaliação - uma nota fortemente determinada, na prática, pelo tempo de serviço do professor e por sua nota anterior, acompanhada por uma curta apreciação - reduzem as margens formais de ação.

\section{FRENTE AOS DESVIOS DA ATIVIDADE DOCENTE}

Como os diretores do ensino secundário percebem essas mudanças? A pesquisa revela que muitos diretores não concordam com a ideia de uma ruptura radical entre sua nova função e seu antigo ofício. Muitos se recusam a admitir tal ruptura, afirmando que se trata de continuar ou prolongar, de modo diferente, a profissão de professor. Uma diretora declara estar particularmente chocada pelo fato de ter sido aconselhada, durante a etapa oral do seu concurso, a suscitar um conflito artificial com os professores a fim de testar suas competências para lidar com a situação! Mas, apesar de tudo, todos revelam uma espécie de ruptura identitária, desejada ou não, perante seus antigos pares, diante dos quais estão, doravante, numa posição hierárquica. E quase todos, quaisquer que sejam suas posturas, descrevem o choque provocado pelo fato de ver "o conjunto das equipes de ensino", ao passo que a visão de um professor facilmente se restringe a um grupo de colegas, ligados pela mesma disciplina de ensino, pelas mesmas turmas ou, ainda, por afinidades pessoais. A novidade reside no contato que passam a ter com certos "desvios da atividade docente", que alguns diretores considerarão limitados a certos indivíduos, e outros como um fenômeno mais geral. $\mathrm{O}$ tema das ausências ou dos atrasos dos professores, mas, também, talvez de forma mais surpreendente, aquele das "incivilidades dos professores", insultos, falas desrespeitosas ou humilhantes dirigidas aos alunos, é amplamente tratado nas entrevistas, com foco na necessidade de controle desses desvios ou da aplicação de sanções. O choque de entrada na profissão, para falar como os sociólogos interacionistas, vem do contato com esta nova realidade de professores que nem sempre fazem seu trabalho de forma satisfatória ou ética (Hughes, 1958).

Evidentemente, quando se interroga os diretores sobre sua motivação diante de suas novas funções, não é ao controle do ensino que eles se referem mais, nem explicitamente ao aumento de seu poder sobre os professores. O poder é obviamente apresentado mais como um aumento do poder de agir ou de "fazer agir" (Crozier; Friedberg, 1977), do que como um poder de controlar ou de impedir. Entretanto, essa é uma face inevitável desse poder. Se o controle dos desvios docentes é uma espécie de "trabalho sujo" em comparação com as missões mais nobres dos diretores, podemos dizer, seguindo, aliás, uma proposta do próprio Everett Hughes (1958), que a profissão de diretor faz tipicamente parte das profissões em que o prestígio de algumas funções permite assumir o trabalho sujo, fazê-lo desaparecer em meio ao conjunto das funções respeitáveis e legítimas relativas, aqui, ao enquadramento do trabalho docente.

\section{“FAZER O ESTABELECIMENTO SE MOVIMENTAR"}

Em contrapartida, os diretores de estabelecimentos de ensino aderem intensamente, no seu conjunto, à ampliação de suas funções, evocada na introdução 
deste artigo. Eles a retraduzem, nas entrevistas, afirmando que não basta "fazer funcionar" um estabelecimento, mas que o essencial é "fazê-lo se movimentar", emplacar um projeto coerente de melhoria que pode assumir várias formas, mas que é definido, em muitos casos, por meio de progressos quantitativos: resultados nos exames, redução das repetições de ano, julgadas ineficientes e dispendiosas, evolução dos fluxos de orientação. As novas funções pedagógicas transversais, que devem se coadunar com a manutenção teórica da completa autonomia pedagógica do professor na sala de aula, encarnam-se, por enquanto, nos estabelecimentos franceses, num verdadeiro empilhamento de dispositivos variados que ficam, de certa forma, a meio caminho entre a sala de aula e o estabelecimento: dispositivos de correção, de auxílio nos deveres de casa, de luta contra o desnivelamento dos alunos, de trabalho em projetos interdisciplinares. Desde 2007, essa situação se recrudesce nos colégios, devido à implantação de um tronco comum de competências, ${ }^{4}$ sobre o qual, infelizmente, a pesquisa é antiga demais para nos fornecer informações. Os diretores de estabelecimentos são, de fato, os pivôs de um movimento de modernização organizacional que eles têm o dever de ajudar a implantar, fazendo com que os professores participem dele.

O controle, muitas vezes, volta-se para o compromisso dos professores com a organização, compromisso cujos indicadores remetem a experiências cotidianas no estabelecimento escolar: os diretores fazem a distinção entre aqueles que "somente cumprem suas cargas horárias" e aqueles que são vistos no estabelecimento ou que frequentam os escritórios da direção. Esse compromisso com os dispositivos e com os projetos é uma base visível, sendo que há um consenso impressionantemente grande entre os diretores de que apenas uma "pequena minoria de professores" (cerca de um terço) o honra. Esse controle tende também a introduzir uma regulação pelos resultados, o famoso "controle dos resultados", com instrumentos externos de regulação colocados à disposição dos estabelecimentos escolares. Passa-se, então, do controle à avaliação, uma palavra que contém, ela própria, uma parte de eufemização, introduzindo a mediação de constatações objetivas, por meio de dados, em sua maioria, quantitativos. Os diretores, sobretudo os principaux de colégios, que trabalham com equipes menores se envolvem cada vez mais em considerações internas sobre as diferenças de resultados das equipes, ou, ainda, em constatações sobre as diferentes escalas de notas dos professores. Resumindo, a avaliação abre margens de incerteza amplamente controladas, por enquanto, pelos diretores de estabelecimentos, na falta de um envolvimento maior, por parte das equipes de ensino, no que poderiam ser diagnósticos sobre situações locais a partir de outra visão. Evidentemente, as iniciativas dos diretores

4 Trata-se, doravante, de avaliar de forma interdisciplinar competências, e não mais simplesmente saberes definidos de forma disciplinar. Esta reforma se choca contra dificuldades de implementação ligadas, particularmente, ao fato de que a avaliação por competências não substituiu a avaliação tradicional, mas se sobrepôs a ela. Para mais esclarecimentos a respeito desta reforma, ver Dominique Raulin (2008). 
dos estabelecimentos são diferentes em função de seu grau de domínio dos dados técnicos ou ainda de sua adesão aos processos, que podem ser por eles interpretados como um controle sobre sua própria ação. Mas a avaliação legitima ações realizadas em nome de resultados objetivos.

\section{A QUESTÃO DO CONFLITO}

Do lado dos professores, essa extensão do domínio de controle se choca com a defesa de sua autonomia profissional, situação que ultrapassa os contornos do mundo da escola. Os professores escaparam, no seu conjunto, da desqualificação profissional por meio das tecnologias educativas, como foi dito nos anos de 1980, mas enfrentam hoje, no seio do próprio estabelecimento, ameaças de restrição à sua autonomia. Ameaças sentidas por eles com maior ou menor intensidade em função da própria concepção sobre seu trabalho enquanto professores, mais ou menos conforme ou adaptada às novas demandas dos diretores. É preciso insistir, aqui, sobre as potencialidades de conflitos presentes, hoje, no processo de enquadramento do trabalho do professor, conflitos esses, aliás, amplamente reconhecidos pelos diretores, mesmo se as versões coletadas são somente as suas. Os diretores falam abundantemente desses conflitos, passados ou presentes, tácitos ou declarados, e os sindicatos de professores, fortes ou fracos, ocupam, na sua opinião, um lugar de destaque. Os diretores se dividem entre aqueles que consideram ter conselhos de administração ${ }^{5}$ "duros" e os outros.

Sob esse aspecto, descrevem-se como "controladores controlados", eles próprios sob o controle de uma hierarquia (reitoria, inspeção de academia), que também acusam de ser cada vez mais exigente e cada vez menos protetora, por exemplo, nos casos de divulgação de seus problemas na mídia. No estado atual das relações sociais e de certa manutenção da força do sindicalismo de ensino, eles se apresentam como atores potencialmente enfraquecidos, às vezes transferidos, mais ou menos a seu pedido ou sob pressão, no caso de conflitos fortes demais com as equipes de professores. O enquadramento e o controle de ensino seriam, portanto, mais do que um trabalho sujo, um trabalho freado ou impossibilitado.

As razões dos conflitos detectadas pela pesquisa são diversas, mas estão frequentemente ligadas ao controle do trabalho do professor. Dizem respeito à diminuição das notas dadas aos professores, a questionamentos de projetos pedagógicos julgados ineficientes, ou ainda aos assuntos discutidos durante o conselho de administração. As sanções feitas aos alunos são também frequentemente motivo de conflito. Os professores acusando os diretores de não apoiá-los; os diretores tentando, o mais das vezes, reduzir o número de expulsões ou de sanções sérias contra alunos no estabelecimento.

5 Os conselhos de administração reúnem seis vezes por ano, aproximadamente, as equipes de direção, os representantes dos professores, das famílias, dos alunos e algumas personalidades externas. Na França, são presididos pelos próprios diretores das escolas. 
A dimensão, potencialmente muito conflituosa, das relações com os professores leva, às vezes, a um tipo de heroização das tarefas de controle. Há algo parecido com isso nas palavras dos diretores quando evocam algumas de suas interações com professores que eles julgam desviantes, como faz um proviseur de liceu profissional que se expressa da seguinte maneira:

Tive que juntar minhas forças, criar coragem, era um professor de 50 anos: "sente-se senhor, tenho coisas desagradáveis para lhe dizer". Ele fazia qualquer coisa com seus alunos. Era realmente qualquer coisa! Num certo momento, explicar que não é possível, que não poderia continuar desse jeito...

Durante conflitos sindicais, eles podem utilizar descrições do gênero "sozinho contra todos”. Às vezes, a heroização adquire uma cor de vitimização. Uma diretora (proviseuse) diz, por exemplo, ter entendido o verdadeiro significado da palavra maldade após um episódio conflituoso com os professores. Mas ela pode ser sinônimo de nobreza moral, por exemplo, no caso da aplicação de sanções a professores que cometeram abusos sexuais contra alunos - os procedimentos implementados são descritos, então, como sendo delicados e desagradáveis, mas, é evidente, como totalmente legítimos. Em muitos casos, as relações sociais de poder são traduzidas e vivenciadas de forma bastante personalizada e, às vezes, na linguagem do assédio no trabalho. Sustentar-se pessoalmente num contexto conflituoso se torna, então, uma competência anunciada como sendo crucial e particularmente legítima quando colocada a serviço da defesa dos alunos.

\section{DO CONTROLE À AVALIAÇÃO, ENTRE BUROCRACIA E PÓS-BUROCRACIA}

Os diretores são, na sua maioria, extremamente críticos, por várias razões, ao modo tradicional de avaliação. Na pesquisa, o conjunto dos diretores o denuncia claramente como "enlouquecedor de tão absurdo", para retomar as palavras de um proviseur, na medida em que o espectro de nota previsto, determinado em grande parte pelo tempo de serviço, não tem muita relação com a real atividade dos professores. Essa avaliação inclui ainda algumas palavras para uma apreciação, limitada pelo pouco espaço deixado no formulário para o julgamento, dando sempre a sensação de que ele não vai “caber”. Ela não permite, tampouco, levar em consideração os problemas relacionais com os alunos, quando eles não se traduzem em atrasos ou erros administrativos. Enfim, os diretores consideram que não têm os meios necessários para reconhecer os professores realmente comprometidos com a escola. Entretanto, não é tão simples adotar o novo modelo, que leva mais em conta o comprometimento com o estabelecimento e a busca de resultados, não somente pela reação dos professores, mas também em razão das novas tarefas que se sobrepõem às tarefas tradicionais de gestão, que não diminuíram muito. A maior parte dos diretores se apoia, ao mesmo tempo, nos dois tipos de funcionamento, um 
que podemos qualificar de burocrático tradicional, focado em regras formais, e o outro, que podemos chamar "pós-burocrático", apoiado sobre as novas modalidades (Maroy, 2006). No cruzamento desses dois modos de regulação, podemos identificar diferentes tipos de estratégias.

\section{STATUS QUO: O DIRETOR BUROCRATA}

Um primeiro grupo de estratégias pouco explícito na pesquisa, já que em evidente contradição com as novas funções, mas certamente muito presente na prática, segundo as palavras dos professores e, às vezes, dos vices - e, além disso, amplamente confirmado pelas tipologias de pesquisas quantitativas (Guillaume, 1997) -, consiste em permanecer no status quo e no controle burocrático oficial de uma atribuição de notas administrativa. Esses diretores também não se envolvem nas novas áreas do controle do ensino.

Entretanto, e como a análise weberiana da burocracia bem o demonstra, este formalismo às vezes se combina com estratégias bastante informais de interpretação das regras, podendo recompensar ou sancionar os professores a partir de critérios pouco transparentes. Não devemos esquecer que, em alguns estabelecimentos, ter o filho do diretor na sua sala de aula é visto como um reconhecimento de alta relevância! Os diretores explicam também de bom grado suas estratégias ou suas astúcias informais: determinado proviseur de liceu profissional manda seu vice falar sobre uma decisão ou uma medida para "sentir" o impacto antes de se envolver nela; outro não hesita em usar seu relacionamento particular com um líder sindical para antecipar as reações dos conselhos de administração, considerados os lugares de discussão mais difíceis. Mas, na nova ordem, esse tipo de estratégia, defasado em relação às novas prescrições, pode ser diferentemente interpretado pelas equipes de professores, ora como um recuo ou uma fuga, e até como um sinal de incompetência, ora como uma posição assumida de freio ante as prescrições modernizadoras e, paradoxalmente, como uma maneira de resguardar a autonomia dos professores. No primeiro caso, o diretor burocrata é julgado como sendo "ausente", no segundo, como protetor de um funcionamento que, afinal, foi por muito tempo considerado eficiente. As pesquisas francesas mostram que essa forma burocrática de funcionamento continua sendo aceitável nos bons estabelecimentos, em que os alunos não apresentam muitos problemas de disciplina, ao passo que, nos estabelecimentos complicados, é percebida como sendo bastante problemática (Van Zanten, 2001).

\section{A AVALIAÇÃO: RUMO AO DIRETOR EXPERT}

Um segundo tipo de estratégia consiste em absorver, sob todas as suas formas, o discurso da avaliação, amalgamando antigos e novos procedimentos. O controle "burocrático", inclusive nas suas margens informais, adquire novos significados, oriundos do novo contexto. Pode-se então dar uma nota administrativa baixa por falta de envolvimento no estabelecimento, mesmo que esse critério não exista explicitamente. É o caso de um principal que sanciona assim mulheres professoras por julgar que elas fazem mal seu trabalho, corrigindo deveres na sala de aula na sexta-feira 
para não terem que trabalhar no fim de semana; informação essa relatada por pais de alunos. Essa decisão the valerá um conflito sindical do qual dirá ter aproveitado para desencadear um diálogo com essas professoras. Pode-se ainda atribuir turmas aos professores em função dos resultados dos alunos nos exames de fim de ciclo, o que era, sem dúvida, feito antes, mas agora recebe uma nova legitimidade no contexto da alta da avaliação. Um principal de colégio destaca que "foi tirando certos professores de certos anos" que seu colégio ganhou alguns pontos na classificação.

A ideia de modernizar essa avaliação, particularmente por meio de entrevistas com os professores, apareceu com bastante frequência na pesquisa, mas ela é mais um ideal regulador para alguns do que uma prática concreta. Quem entrevistar? Na maior parte do tempo, é impossível convocar todo mundo no mesmo ano, até nos colégios, que contam com equipes de 40 a 50 professores. Aqueles que têm dificuldades? Isso pode parecer estigmatizante demais... Os jovens? Não são obrigatoriamente eles que constituem os casos mais problemáticos. Uma proviseure de liceu profissional organiza entrevistas em torno do projeto do estabelecimento, a fim de garantir que os professores o conheçam; ela lhes pede também que relatem como se inscrevem nesse projeto. Essa proviseure descreve um passado muito conflituoso com as equipes, ainda que não estabeleça uma relação explícita entre essa prática e tais conflitos. A maior parte dos diretores afirma que gostaria de melhor avaliar para aumentar seu conhecimento: sobre o compromisso, sobre os projetos etc. Impedidos de fazê-lo, eles se voltam, mediante algumas horas suplementares, para os meios informais que estão ao seu dispor: atribuições de agendas ou de turmas adaptadas a tal ou qual projeto, valorizações verbais de determinados professores, pedidos de tomadas de responsabilidades ou de coordenação.

Alguns diretores tentam explorar plenamente as novas zonas de incerteza criadas pela gestão por meio de resultados, investindo o máximo possível na criação de uma expertise local.

Os projetos realizados no âmbito do estabelecimento, mais acessíveis à intervenção do diretor do que o que ocorre dentro de cada sala de aula, são, então, palco das expertises, às vezes acopladas aos resultados dos testes padronizados. Por exemplo, num dado colégio, a equipe de direção determinou o fim de um projeto chamado "Livros em festa", realizado há quatro anos por professores de francês e que consistia na organização de encontros entre escritores e alunos. O projeto foi questionado em função dos resultados escolares decepcionantes nessa disciplina. A equipe de direção falou, a esse respeito, de "menos valia", e se apoiou numa análise bastante técnica sobre as diferenças de resultados entre a avaliação dos alunos na $5^{\mathrm{a}}$ série e a avaliação dos alunos na $8^{\mathrm{a}}$ série. Em outro estabelecimento, considerado muito problemático, um projeto de revezamento que visava tirar da sala os alunos perturbadores demais e lhes oferecer um atendimento mais individualizado foi suprimido. Segundo a fala da diretora, esse projeto não fazia baixar nem o número de conselhos de disciplina, nem o número de expulsões.

Mas os diretores vivenciam, às vezes, em cheio, a tensão entre a questão do envolvimento e da eficiência. O que fazer quando professores muito pouco envolvidos 
obtêm, no entanto, excelentes resultados? Como convencê-los a se envolverem mais? $\mathrm{E}$ o que deve ser feito quando equipes extremamente mobilizadas não melhoram seus resultados? Como fazer para que elas não desanimem? Alguns diretores privilegiam o envolvimento em detrimento dos resultados de um projeto, muitas vezes difícil de avaliar. Mas, em geral, os diretores parecem privilegiar a avaliação, ou seja, o papel de árbitro, se pensarmos na tensão "árbitro-treinador" formalizada por Pierre Merle (1996) a propósito da avaliação dos alunos pelos professores. Mais uma vez, antigos procedimentos podem ser colocados à disposição de novos objetivos: um principal dirá ter melhorado seus resultados no exame do brevet ( $8^{a}$ série) fazendo com que certos professores não atuem mais em certas turmas.

A estratégia do diretor expert se choca, na prática, com a falta de tempo para investir numa operação delicada, mas também com a falta de competência para se chegar a conclusões e operar interpretações difíceis. Muitas vezes, a construção de uma expertise local ocorre pelo prisma deformador de uma necessidade imediata de ação: o efeito-escola, esse diferencial de eficácia, colocado em evidência pelas pesquisas, é de difícil explicação, levando os diretores a superestimar sua ação em detrimento dos efeitos de contexto ou de públicos, cujo nível continua sendo a principal fonte de eficácia identificada pelas pesquisas. ${ }^{6}$ Além disso, essa expertise local raramente é equilibrada por polos de contraexpertise, nos quais se discutiria verdadeiramente sobre "pedagogia". É impressionante constatar que diretores que propõem projetos inovadores em matéria de pedagogia são geralmente contestados pelas equipes de professores pela sua maneira de exercer a autoridade, e não pelo próprio conteúdo do projeto. Um proviseur, que queria reestruturar todo o seu estabelecimento em torno do desenvolvimento sustentável, estava em conflito com os professores a respeito da data de fechamento do estabelecimento para as revisões dos exames. Portanto, essas expertises são também marcadas pela ausência de deliberação, ou de contraexpertise, quando poderiam ser constituintes de polos reguladores de discussão (Derouet; Dutercq, 1997).

\section{O CONTROLE COMO APOIO: O DIRETOR COACH}

Outro tipo de estratégia consiste em implantar controles e avaliações de uma maneira eufemizada sob a forma de auxílio, de escuta, e até, em alguns casos, de quase acompanhamento, que vem confundir a intenção hierárquica e liberar a palavra sobre os problemas. Os diretores de recursos humanos estão, às vezes, mais próximos do trabalho real do que os sindicatos, na observação de Christophe Dejours em Souffrance en France (1998), sendo que essa observação pode, sem dúvida, encontrar também uma realidade numa escola onde os líderes sindicais, igualmente carismáticos na sala de aula, parecem em certos momentos bastante afastados das dificuldades mais "vergonhosas" de seu colega. Os problemas relativos à falta de

6 Vale lembrar que na França não existe uma influência nítida comprovada das práticas dos diretores sobre o desempenho dos estabelecimentos, ao contrário do que acontece nos países anglo-saxões (Meuret, 2003). 
disciplina, de autoridade, de domínio de turma podem ser geridos pelos diretores de duas formas bem diferenciadas. Numa configuração burocrática, os diretores não precisam cuidar disso, já que esses problemas acontecem no espaço da sala de aula. Mas, no novo modelo, considera-se que tais problemas transbordam o espaço da sala de aula e devem, portanto, receber um tratamento como sendo algo que faz parte do estabelecimento. Em algumas escolas, são exatamente esses problemas que geram mais transtornos: queixas de pais, contestação de sanções e, até, por vezes, de professores, como num liceu em que um coletivo de alunos se queixou de um professor diretamente ao inspetor, um fato que não agradou o diretor.

Os pedidos de sanções e de reuniões de conselhos de disciplina, instâncias que podem decidir pela exclusão definitiva de um aluno, são muito frequentes em alguns estabelecimentos e são objeto de desafios importantes nas relações entre professores e diretores. Portanto, os diretores também podem ser divididos entre aqueles que assumem e aqueles que não assumem o árduo trabalho de tentar endireitar a "desordem escolar". Essa questão, ignorada nas definições das novas funções dos diretores, em que se trata de animar ou impulsionar políticas pedagógicas, mas nunca de auxiliar na resolução das dificuldades dos professores, é, entretanto, muito importante no dia a dia. Alguns diretores podem, então, adotar práticas que se aproximam, mais ou menos, do acompanhamento: da passagem diante das portas das salas de aula nas horas difíceis, até a proteção frente à inspeção, retirando os alunos problemáticos da sala de aula, passando pela simples escuta das dificuldades que, por si só, já pode ser uma grande devoradora de tempo, como o expressará o diretor de um colégio:

O problema não é escutar os professores, todos os colegas the falarão sobre escuta, o problema é reescutá-los.

Mas o diretor encontra-se, também, no espaço estratégico em que informações oriundas de fontes diversas se cruzam: membros da equipe de direção, ${ }^{7}$ alunos, evidentemente, e, cada vez mais, pais de alunos. Quanto maior o estabelecimento, mais importante se torna esse controle informal, como diz o proviseur de um grande estabelecimento escolar. $\mathrm{O}$ apoio passa também pela gestão informal destas informações, inclusive em termos de auxílio coletivo:

O professor que não segura sua turma, a gente sabe por meio da rádio-corredor ou porque incidentes aconteceram. Tentamos vê-lo, ajudá-lo. Não somente eu, mas também o vice-diretor, o orientador educacional. Mas, a gente não consegue resolver tudo...!

$\overline{7 \text { As equipes de }}$ direção francesas são formadas pelo diretor, principal ou proviseur, seu vice, o intendente ou gestor e os conselheiros principais de educação encarregados da gestão disciplinar e da animação educativa do estabelecimento. 
Portanto, está claro que uma das maneiras que o diretor usa para gerir as novas funções é trocar informalmente essas novas modalidades de controle por um apoio maior aos professores em dificuldades com os alunos. Essa estratégia permite ao diretor se adequar às novas prescrições no que tange à avaliação e ao envolvimento dos professores, desarmando os conflitos que poderiam surgir devido à impressão dos professores de que estão perdendo sua autonomia pedagógica. É o que ocorreu num colégio considerado problemático onde realizamos uma observação etnográfica durante um ano e no qual a estratégia principal do diretor consistia em apoiar muito abertamente os professores no seu trabalho cotidiano frente aos alunos, em troca de seu envolvimento em vários projetos (Barrère, 2010). Ele usava a lógica da avaliação no interior dessa dinâmica de maneira interessante. Por exemplo, quando os inspetores de matemática questionaram, no momento de uma auditoria, os professores desse colégio, em função dos resultados ruins obtidos aquele ano, o diretor fez uma verdadeira contraperícia, mostrando que, caso fossem considerados os três últimos anos e não apenas um, os resultados seriam positivos. Uma das justificativas para essa ação junto ao inspetor é que essa equipe de professores era particularmente motivada: o apoio diante do inspetor é, então, um tipo de recompensa informal para fortalecer o envolvimento dos professores com o estabelecimento. Mas esse apoio aos professores pode também se tornar uma tarefa devoradora de tempo e energia que se acrescenta às outras funções.

\section{EM BUSCA DE UMA HIERARQUIA INTERMEDIÁRIA: O DIRETOR POLITICO}

Enfim, se o campo de ação formal constituído em torno do coletivo de professores é sobretudo ligado às relações e à força dos sindicatos, alguns diretores parecem estar à procura de outras estruturas intermediárias entre a direção do estabelecimento e o conjunto dos professores. Esses intermediários são professores que aceitam missões de coordenação, responsabilidades de animação e de gestão de dispositivos. Em 2007, um conselho pedagógico foi implantado para discutir projetos do estabelecimento, mas teve dificuldade para desempenhar um verdadeiro papel de harmonização porque os professores designados pelo diretor eram pouco representativos de seus colegas.

Frente aos antigos coletivos de ensino, grupos disciplinares ou sindicais, ou aos novos coletivos relativos a projetos, os diretores constroem alianças móveis e flexíveis, visando sistematicamente à participação de um maior número de atores na organização e no controle da atividade. A ideia é delegar uma parte de seu poder aos pares, numa estratégia próxima à do empowerment. Mas, na prática, constatam-se, por enquanto, três tipos de tensões:

- Num contexto em que, às vezes, é a colegialidade forçada (Hargreaves, 1994) que prima sobre a iniciativa dos atores, os diretores encontram bastante dificuldade em reconhecer coletivos informais que eles não dominam, quando estes não se inscrevem em projetos explícitos ou nas perspectivas que eles próprios definem. Como diz Norbert Alter (2009), 
as organizações sabem tomar, mas não sabem receber. Ora, esses coletivos informais, às vezes questionados pelas novas modalidades de trabalho, podem ser importantes vetores de envolvimento e de colaboração (Barrère, 2002);

- Em segundo lugar, pode ser difícil para os diretores resistirem à tentação de eles próprios configurarem novos coletivos em torno de projetos e tentar envolver os professores neles. Esses projetos podem ser muito pessoais, particularmente quando o diretor foi um professor "inovador pedagógico". Esses profissionais têm certezas que os levam a apoiar ou a sancionar determinados tipos de projetos. Por exemplo, um certo proviseur se centrou exclusivamente na animação cultural ou no teatro, outro no meio ambiente. Uma principale se envolveu num projeto de iniciação à arquitetura, um proviseur elaborou, com entusiasmo, para restaurar a relação social no seu estabelecimento, um ambicioso projeto de jogo de xadrez que deveria animar os recreios: os tabuleiros ficaram mofando num ginásio por meses até que ele admitisse que não deu certo;

- Por fim, é difícil não tentar opor os novos formatos de coletivos aos coletivos sindicais. O conselho pedagógico, instaurado após esta pesquisa e do qual já falamos, estava presente nos discursos dos diretores como possibilidade e até como necessidade a fim de contornar os conselhos de administração, fortemente penetrados pelos sindicatos. Evidentemente, tal situação apenas contribui para dividir as equipes de ensino. Como contraexemplo, podemos citar um liceu onde um líder sindical atuante no campo pedagógico organizou novos dispositivos de apoio ao trabalho dos alunos, contestando, ao mesmo tempo, um agrupamento de repetentes proposto pelo diretor, assim como novos dispositivos de avaliação. Esse professor, membro do principal sindicato docente do ensino secundário, o SNES, se envolveu em dispositivos como o auxílio aos deveres dos sindicalistas que não parecem muito convencidos deles, mas também no domínio da discussão e da contestação de assuntos que parecem ser da alçada exclusiva do diretor. Ele conseguiu, assim, entrar em conflito com os novos desafios e configurações do trabalho docente. Mas esse foi um caso que figurou como marginal na pesquisa. As equipes de ensino, por turmas ou disciplinas, são frequentemente lembradas pelos diretores como espaços possíveis para a resolução dos problemas, mas sua existência real é bastante variável, pois os coletivos de ensino raramente são constituídos em torno de suas próprias dificuldades na matéria ou em torno de deliberações de ordem pedagógica. A questão da avaliação também pode ser recolocada neste âmbito. No momento em que as prescrições de trabalho coletivo são cada vez mais fortes, será que é razoável restringir-se a avaliações puramente individuais ou, ao contrário, seria preciso passar para avaliações coletivas, como já começa a acontecer em alguns estabelecimentos, sem que isto seja, por enquanto, um procedimento formalizado? 
Geralmente, é difícil que as políticas e os projetos de cada estabelecimento sejam objeto de discussões coletivas institucionalizadas no âmbito escolar. Entretanto, assuntos não faltam: seria melhor incentivar uma multiplicidade de ações inovadoras ou um único grande projeto? Como escolher entre projetos focados no coração da atividade escolar e projetos de motivação, de enriquecimento cultural, de saídas da escola? Na maior parte do tempo, essas escolhas são feitas somente pelas equipes de direção. Não são objeto de discussões e tomadas de decisão democráticas. Alguns diretores, apesar de tudo, tentam favorecer esses procedimentos coletivos, e também fazer com que as equipes de ensino encontrem meios de solucionar as dificuldades encontradas na sala de aula.

\section{CONCLUSÃO}

Como diz o sociólogo Norbert Alter (2000), sem fazer uma referência particular ao mundo escolar, o mundo do trabalho e das organizações oscila, hoje, constantemente, entre a manutenção e mesmo o fortalecimento dos procedimentos de controle burocrático e sua contestação, visando à introdução de outros modos de controles, mais flexíveis, capazes de responder aos eventos e com preocupações de eficiência. É exatamente o que está acontecendo nos estabelecimentos escolares franceses, onde os incentivos à avaliação - dos estabelecimentos, dos professores - coexistem, hoje, com procedimentos bastante formais de controle. O estabelecimento burocrático ainda não foi substituído pelo "pós-burocrático", os dois se sobrepõem, numa espécie de confusão organizacional que pode dar a impressão, aos professores, de um vai e vem permanente entre um sistema e outro.

De fato, os diretores evoluem, doravante, num mundo complexo, em que são constantemente chamados a construir uma aliança entre modernidade organizacional e valores tradicionais da escola republicana - igualdade de oportunidades, integração das diferenças sociais -, o que exige certo número de "tradutores" para que se possam construir passagens tranquilas de um ao outro, justificando as ações ante professores que temem perder sua autonomia pedagógica. Dois desses argumentos são fortemente legitimadores da ação dos diretores e do controle do ensino. O primeiro pode ser chamado "a defesa dos alunos" que têm "direito" a suas horas de aula, mas também ao "respeito" dos professores, ou a professores envolvidos e eficientes, ainda mais por serem escolarizados em estabelecimentos relegados. Essa defesa dos alunos é, ao mesmo tempo, uma defesa dos usuários - na nova gestão pública - e uma ligação com palavras de ordem tais como "igualdade de oportunidades" ou, na linguagem dos diretores, certamente inspirada pelo relatório americano, No child left behind, não se deve "deixar ninguém pelo caminho". O segundo argumento, que facilita a referida passagem, é a avaliação em si, que responsabiliza os atores em nome de uma evidência de resultados, ou melhor, dos diferenciais de resultados da ação educativa, sobretudo nas zonas marcadas pelo fracasso escolar. Argumento dificilmente combatido ou contestado em seu princípio, nem mesmo pelos sindicatos. 
Os diretores, de modo geral, são favoráveis a essa nova realidade organizacional, que lhes dá mais poder. Entretanto, sofrem muitas tensões no seio dessa situação híbrida. Por um lado, eles se veem como tendo pouquíssimos meios reais de sanção sobre os professores, exceto quando se trata de casos extremos. Por outro, enfrentam situações que podem ser fortemente conflituosas quando os professores temem pela sua autonomia ou vivem a ampliação de suas funções na escola como uma obrigação sem contrapartida real. Eles tentam, então, negociar o comprometimento do professor com o ensino trocando-o por apoio nas dificuldades comuns da sala de aula. Por fim, cabe dizer que a emergência das novas tarefas pedagógicas e de expertises exigidas pelas novas regulações não se traduziu na diminuição das tarefas administrativas tradicionais, colocando os diretores diante de um permanente risco de sobrecarga de trabalho ou da necessidade de escolhas que os levam a reduzir ao mínimo possível as tarefas oriundas de suas novas missões (Maroy, 2002).

\section{REFERÊNCIAS}

Alter, Norbert. L'innovation ordinaire. Paris: PUF, 2000.

Donner et prendre: la coopération en entreprise. Paris: La Découverte, 2009.

BARrère, Anne. Les enseignants au travail. Paris: L'Harmattan, 2002.

Sociologie des chefs d'établissement. Paris: PUF, 2006.

Ce que l'évaluation fait aux établissements scolaires. Une année dans un collège d'«éducation prioritaire». Ethnologie Française, Paris: PUF, v. 40, n. 1, p. 141-149, 2010. Crahay, Marcel; Mons, Nathalie. L'évaluation des performances scolaires des élèves: un instrument d'évaluation des politiques éducatives? In: Felouzis, Georges; Hanhardt, Siegfried. Gouverner l'éducation par les nombres. Bruxelles: De Boeck, 2011. p. 77-99.

Crozier, Michel; Friedberg, Erhard. L'acteur et le système. Paris: Seuil, 1977.

Dejours, Christophe. Souffrance en France. Paris: Seuil, 1998.

Derouet, Jean-Louis; Duterce, Yves. L'établissement scolaire, entre service public et autonomie locale. Paris: ESF, 1997.

Duterce, Yves. Politiques éducatives et évaluation. Paris: PUF, 2000.

Forestier, Christian; Thélot, Claude; Emin, Jean-Claude. Que vaut l'enseignement en France? Paris: Stock, 2007.

Guillaume, Jean-François. Typologie des chefs d'établissement en fonction de leurs conceptions pédagogiques. Education et formations, Mons: UMONS, n. 49, p. 21-22, mars 1997.

Hargreaves, Andy. Changing teachers, changing times: teacher's work and culture in the post modern age. New York: Teachers College Press, 1994.

Hughes, Everett. Men and their work. Glencoe: Free Press, 1958.

Maroy, Christian. L'enseignement secondaire et ses enseignants. Bruxelles: De Boeck, 2002. 
École, régulation et marché. Paris: PUF, 2006.

Merle, Pierre. Lévaluation des élèves. Paris: PUF, 1996.

Meuret, Denis. Efficacité et équité des collèges. L'effet établissement. In: Derouet, Jean-Louis (Dir.). Le collège unique en question. Paris: PUF, 2003. p. 49-65.

Raulin, Dominique. Du socle commun aux compétences. Paris: Hachette éducation, 2008. Van Zanten, Agnès. L'école de la périphérie. Paris: La Découverte, 2001.

\section{SOBRE A AUTORA}

Anne Barrère é doutora em sociologia pela Universidade de Bordeaux 2. Professora das Universidades de Paris 3 e 5. E-mail: anne.barrere@parisdescartes.fr

Recebido em agosto de 2011 Aprovado em dezembro de 2011 


\section{ANNE BARRÈRE}

\section{Controlar ou avaliar o trabalho docente? Estratégias dos diretores numa organização escolar híbrida}

Desde a descentralização dos anos de 1980 e, ainda mais, desde o fortalecimento da avaliação no âmbito das políticas educativas nos anos 2000, os diretores de estabelecimentos de ensino secundário na França viram crescer a sua função no que diz respeito à supervisão do trabalho dos professores. $\mathrm{Na}$ teoria, esses profissionais, antes focados principalmente no trabalho administrativo, deveriam agora voltar sua ação para o trabalho pedagógico da escola, acompanhando, assim, o desempenho dos alunos. Entretanto, na prática, as estratégias dos diretores variam segundo os contextos. Na maior parte do tempo, essas estratégias articulam formas antigas e novas de regulação. Este artigo se propõe a analisá-las com base em uma pesquisa qualitativa realizada em 2005, junto a 40 diretores de escolas secundárias no norte da França. Considerando que a avaliação é frequentemente descrita a partir de perspectivas sistêmicas e macrossociais, faz-se necessário entender o que ela produz no cotidiano dos estabelecimentos escolares.

Palavras-chave: escolas; diretores; professores; controle; avaliação.

Controlling or evaluating teachers' work? Strategies of principals in a hybrid school

Since the decentralization of the 1980s and even more since the strengthening of evaluation within educational policy in the 2000s, the functions of principals of secondary schools in France grew with regard to the supervision of the work of teachers. In theory, these professionals, who before focused mainly on office work, should now turn their action to the educational work of the school, following thus the performance of students. However, in practice, the strategies of the principals vary according to the context. Most of the time, these strategies articulate old and new forms of regulation. This article aims to analyze them on the basis of a qualitative study conducted in 2005, with 40 secondary school principals in northern France. Taking into account that evaluation is often described from systemic and macro social perspectives, it is necessary to understand what it produces in the daily lives of schools.

Keywords: schools; principals; teachers; control; evaluation. 


\section{¿Controlar o evaluar el trabajo docente? Estrategias de los directores en una organización escolar híbrida}

Desde la descentralización escolar de los años 1980 y, sobre todo, desde la generalización de la evaluación en las politicas educativas en los años 2000, los directores de los centros educativos secundarios en Francia han visto su función incrementada en lo que concierne a la supervisión del trabajo de los profesores. El control casi exclusivamente administrativo que ejercian hasta hace poco ha dado lugar, al menos en teoria, a una evaluación más cercana al trabajo real, que debe tener en cuenta el desempeño de los alumnos. Sin embargo, en la práctica, las estrategias de los directores de colegios son muy diversas según los contextos, cruzándose por lo general las antiguas formas de regulación con las nuevas. Este articulo se propone analizar estas prácticas a partir de una investigación cualitativa realizada en el 2005 con cuarenta directores de escuela en el norte de Francia. Teniendo en cuenta que frecuentemente la evaluación se describe a partir de perspectivas sistémicas y macrosociales, es necesario entender las consecuencias que produce en el cotidiano de los centros educativos.

Palabras clave: centros educativos; directores; profesores; evaluación; supervisión. 